\title{
Perancangan Ulang Kursi Kuliah Yang Ergonomis Di Universitas Islam BANDUNG JL. TAMANSARI NO.1 BANDUNG
}

\section{REDESIGN OF ERGONOMIC LECTURE CHAIR IN ISLAMIC UNIVERSITY BANDUNG JL. BANDUNG NO.1 TAMANSARI}

\section{${ }^{1}$ Eri Achiraeniwati, ${ }^{2}$ Yanti Sri Rejeki, ${ }^{3}$ Nur Rahman As'ad dan ${ }^{4}$ Widi Pratama}

Jurusan Teknik Industri, Universitas Islam Bandung, Jl. Tamansari No. 1 Bandung 40116

e-mail: ${ }^{1}$ eri_ach@yahoo.co.id, ${ }^{2} y s r 2804 @ g m a i l . c o m,{ }^{3}$ nur_asad@yahoo.co.id, ${ }^{4}$ mwidiekap@gmail.com

\begin{abstract}
Bandung Islamic University (Universitas Islam Bandung - Unisba) is one of private universities in Bandung, West Java. Unisba's vision is "To be an independent and prominent university in Asia." One of the efforts to achieve the vision is by improving the quality of the learning process. A good quality of learning process can be influenced by the physical environment of the classroom. Every classroom in Unisba has been equipped with learning facility as supporting infrastructure in the learning process. The facilities are chair/bench study, whiteboard, projector screen, and classroom environment. Such facilities are still thought to be uncomfortable, especially the ones at Jl. Tamansari no. 1. Survey questionnaires were distributed to a total of 40 students, with 11 students from Faculty of Psychology, 9 students from Faculty of Engineering, 8 students from Faculty of Economy, and 12 students from Faculty of Communication. According to the survey, it is found that the most uncomfortable facility that needs to be fixed is study/lecture chairs. There is a need to re-design thelecture chairs in Unisba by taking into account the demand from the users and the ergonomic aspect. This research used Ergonomic Function Deployment (EFD) and Antropometri methods. The data for this research was generated by distributing the Nordic body map questionnaires to understand students' complaint and demand for lecture chairs, as well as to identify the average body measure in order to get the right measurement for the lecture chairs. The questioners were distributed to 98 respondents, who represented Faculty of Psychology, Engineering, Economy, and Communication. The result of this research is a design for the lecture chairs according to the demand of the students and the measurement of the students' body who are studying at Unisba's Jl. Tamansari No. 1 campus.
\end{abstract}

Key words: lecture chair, ergonomic, EFD, anthropometry 


\begin{abstract}
Abstrak. Universitas Islam Bandung (Unisba), merupakan salah satu universitas swasta yang berada di Bandung Jawa Barat. Unisba memiliki visi " Menjadi Perguruan Tinggi Islam yang mandiri, dan terkemuka di Asia”. Salah satu upaya dalam mewujudkan visi tersebut adalah dengan meningkatkan kualitas pembelajaran. Kualitas belajar yang baik dapat dipengaruhi oleh faktor lingkungan fisik kelas. Setiap ruang kelas yang ada di Universitas Islam Bandung (Unisba) telah dilengkapi fasilitas pembelajaran sebagai sarana pendukung dalam proses pembelajaran. Fasilitas yang tersedia terdiri dari kursi kuliah, papan tulis, layar proyektor dan lingkungan kelas. Fasilitas tersebut masih dirasakan kurang nyaman, khususnya pada kelas yang berada di Jl. Tamansari No.1. Berdasarkan hasil kuesioner mengenai fasilitas kelas yang dirasakan belum nyaman dan perlu diperbaiki terhadap 40 mahasiswa, yang terdiri dari 11 mahasiswa Fakultas Psikologi, 9 mahasiswa Fakultas Teknik, 8 mahasiswa Fakultas Ekonomi, dan 12 mahasiswa Fakultas Komunikasi, menunjukan bahwa fasilitas yang paling dirasakan belum nyaman dan perlu diperbaiki adalah kursi kuliah. Oleh karena itu perlu dilakukan perancangan ulang terhadap kursi kuliah di Unisba dengan memperhatikan keinginan pengguna dan aspek ergonomis. Metode yang digunakan untuk penelitian ini adalah metode Ergonomic Function Deployment (EFD) dan Antropometri. Data yang digunakan dalam penelitian ini diperoleh dengan cara menyebarkan kuesioner Nordic body Map untuk mengetahui keluhan yang dirasakan oleh mahasiswa terhadap penggunaan kursi kuliah, kuesioner keinginan mahasiswa terhadap kursi kuliah, dan pengukuran dimensi tubuh untuk memperoleh ukuran kursi kuliah yang sesuai dengan ukuran mahasiswa. Jumlah responden sebanyak 98 responden, yang mewakili Fakultas Psikologi, Teknik, Ekonomi dan Komunikasi. Hasil dari penelitian ini adalah rancangan kursi kuliah yang sesuai dengan keinginan dan ukuran tubuh mahasiswa pengguna kursi kuliah yang ada di Kampus Unisba Jl. Tamansari No. 1.

Kata kunci : kursi, ergonomis, EFD, Anthropometri
\end{abstract}




\section{Pendahuluan}

Tingkat konsentrasi mahasiswa merupakan salah satu faktor yang menentukan baik buruknya kualitas belajar mahasiswa dalam perkuliahan. Kualitas belajar yang baik dapat dipengaruhi oleh faktor lingkungan fisik kelas yang digunakan mahasiswa dalam proses belajar mengajar. Pada prinsipnya lingkungan fisik kelas yang baik adalah ruang kelas yang menarik, efektif dan mendukung mahasiswa dan dosen dalam proses pembelajaran (Winzer, 1998; 16).

Setiap ruang kelas yang ada di Universitas Islam Bandung (Unisba) telah dilengkapi fasilitas pembelajaran sebagai sarana pendukung dalam proses pembelajaran. Fasilitas yang tersedia terdiri dari kursi kuliah, papan tulis, layar proyektor dan lingkungan kelas. Fasilitas tersebut masih dirasakan kurang nyaman, khususnya pada kelas yang berada di Jl. Tamansari No.1. Berdasarkan hasil kuesioner mengenai fasilitas kelas yang dirasakan belum nyaman dan perlu diperbaiki terhadap 40 mahasiswa, menunjukan bahwa fasilitas yang paling dirasakan belum nyaman dan perlu diperbaiki adalah kursi kuliah.

Berdasarkan hasil wawancara singkat kepada mahasiswa yang rata-rata setiap harinya duduk di kelas selama 5 sks atau 250 menit. Keluhan yang dirasakan oleh mahasiswa yang menggunakan kursi kuliah yang ada saat ini adalah sakit leher karena leher yang menekuk, nyeri punggung akibat alas sandaran tidak menompang badan, kaki pegal karena posisi yang tidak nyaman saat duduk, tidak nyaman saat menulis karena terganggu sandaran dan alas meja yang kaku membuat mahasiswa harus menyerongkan badan ketika akan duduk. Berdasarkan kondisi tersebut perlu dilakukan perancangan ulang terhadap kursi kuliah di Unisba dengan memperhatikan keinginan pengguna dan aspek ergonomis.

\section{Metode Penelitian}

Metode penelitian yang digunakan dalam penelitian ini adalah metode penelitian kuantitatif deskriptif, yaitu dengan cara mencari informasi tentang gejala yang ada, didefinisikan dengan jelas tujuan yang akan dicapai, merencanakan cara pendekatannya, mengumpulkan data sebagai bahan untuk membuat laporan. Tahapan yang dilakukan dalam penelitian ini adalah sebagai berikut:

1. Pengumpulan data dilakukan dengan melakukan pengukuran dimensi kursi kuliah untuk tiga tipe kursi kuliah yang digunakan.Hasil pengukuran ini didapat data ukuran dari setiap dimensi kursi kuliah. Selain itu melakukan penyebaran kuesioner keinginan mahasiswa terhadap kursi kuliah. Kuesioner disebarkan kepada 98 responden.

2. Pengolahan Data dan Pembahasan

Kegiatan pada tahapan ini adalah merancang produk berdasarkan hasil dari pengumpulan data pada kegiatan sebelumnya. Pembuatan rancangan terdiri dari dua tahapan, yaitu:

a. Tahapan pertama, menterjemahkan data keinginan pengguna dan aspek ergonomi menggunakan metode Ergonomic Function Deployment (EFD).

b. Tahapan kedua, menentukan dimensi-dimensi tubuh yang sesuai dengan produk yang diinginkan konsumen dan aspek ergonomis. Selanjutnya melakukan pengukuran dimensi-dimensi tubuh terkait tersebut pada responden yang telah ditentukan. Hasil dari pengukuran tersebut digunakan sebagai ukuran pada dimensi kursi yang dirancang. Tahapan kedua ini menggunakan metode anthropometri. 


\section{Hasil dan Pembahasan}

Produk yang akan dirancang dengan menggunakan metode EFD adalah kursi kuliah yang ergonomis dengan spesifikasi yang sesuai dengan keinginan dan kebutuhan mahasiswa/i. Menurut Sutajaya (2007) Penerapan kursi yang ergonomis dapat mencegah lebih dini berbagai gangguan kesehatan mahasiswa/i dan membentuk sikap tubuh yang benar, mengurangi kelelahan, lebih berkonsentrasi dan akhirnya secara keseluruhan akan dapat meningkatkan sumber daya manusia untuk lebih berkualitas baik dari segi derajat kesehatannya maupun pada peningkatan kemampuan/konsentrasi dalam belajar.

Hasil kuesioner yang telah didapat, menjadi sumber untuk perancangan kursi kuliah dengan menggunakan metode Ergonomic Function Deployment (EFD) dan ukuran dimensi mahasiswa digunakan untuk menentukan ukuran dimensi kursi dan meja. Adapun tahapan-tahapan yang dilakukan pada penelitian ini adalah sebagai berikut:

1. Pembuatan Matriks Perencanaan (Fasa 1)

2. Pengembangan Matriks Perencanaan Komponen (Fasa 2)

3. Perancangan berdasarkan Ergonomi Antropometri

\section{Matriks perecanaan (Fasa 1)}

Pada Matriks Perencanaan ini dibutuhkan data keinginan mahasiswa dan kebutuhan kursi yang ergonomis, yang selanjutnya diolah untuk mendapatkan tingkat kepentingan kebutuhan mahasiswa, tingkat kepuasan, dan tujuan strategis produk yang akan dikembangkan. Langkah selanjutnya menterjemahkan kebutuhan dan keinginan mahasiswa/i kedalam persyaratan teknis (HOWs). Hasil dari pendeskripsian persyaratan teknis adalah sebagai berikut :

1. Fungsi kursi, terkait dengan aktivitas yang dilakukan selama duduk dikursi kuliah. Fungsi kursi dibuat untuk menunjang/mempermudah mahasiswa/i dalam melakukan aktivitas dikursi kuliah.

2. Desain kursi, dibuat mengikuti fungsi dan ukuran yang diinginan oleh pengguna. Desain kursi membantu agar kursi yang dibuat enak dilihat oleh pengguna.

3. Bahan kursi, bahan baku yang digunakan menggunakan pipa besi sebagai rangka kursi, writing pad sebagai alas tulis yang menggunakan bahan kayu utuh tanpa sambungan dan alas tulis serta sandaran menggunakan bahan kayu yang dilapisi busa. Bahan baku yang dipilih diharapakan dapat sesuai dengan kebutuhan dan keinginan mahasiswa/i.

4. Ukuran kursi, ukuran sangat penting dalam menentukan setiap dimensi. Dimana dalam penelitian ini untuk menentukan sebuah ukuran dimensi kursi harus memperhatikan dimensi tubuh penggunanya.

5. Stabilitas kursi, meliputi kestabilan pada kaki kursi dan alas meja agar kursi yang digunakan rata dengan permukaan lantai serta alas meja yang lurus ketika digunakan.

Tahap selanjutnya dalam membangun rumah kualitas dengan menjelaskan tingkat kekuatan hubungan antara kebutuhan dan karakteristik teknis dengan mencatatnya dalam sel-sel matriks. Matriks perencanaan produk (House of Ergonomic) seluruhnya dapat dilihat pada Gambar 1. 


\section{Pengembangan Matriks Perencanaan Komponen (Fasa 2)}

Perencanaan komponen merupakan proses penerjemahan dan pengembangan karakteristik teknik yang dibutuhkan saat membuat kursi kuliah pada matriks fasa 1 menjadi lebih detail dan membentuk karakteristik komponen pada Gambar 2.

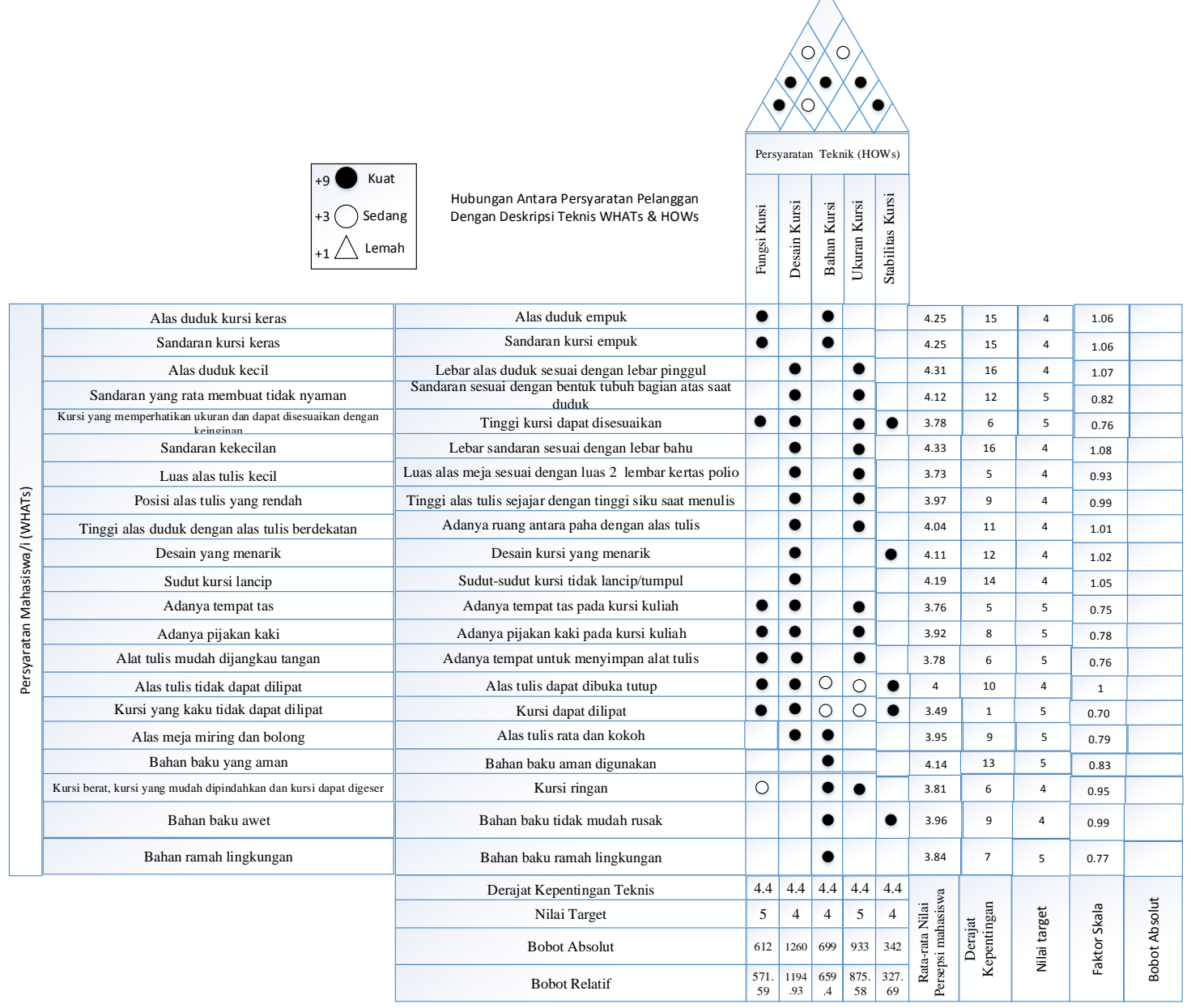

\section{Gambar 1. Perencanaan Produk (House of Ergonomic)Fasa 1}

\section{Hasil Pengembangan Matriks Fasa 1 dan Fasa 2}

Berdasarkan hasil dari pengembangan matriks Ergonomic Function Deployment (EFD) fasa 1 dan fasa 2 maka didapatkan prioritas yang harus diperhatikan dalam pembuatan kursi kuliah baru yang digunakan di Universitas Islam Bandung (UNISBA). Karakteristik teknis berdasarkan urutan prioritas utama sesuai dengan bobot absolut pada matriks perencanaan komponen dapat dilihat pada Tabel 1. 


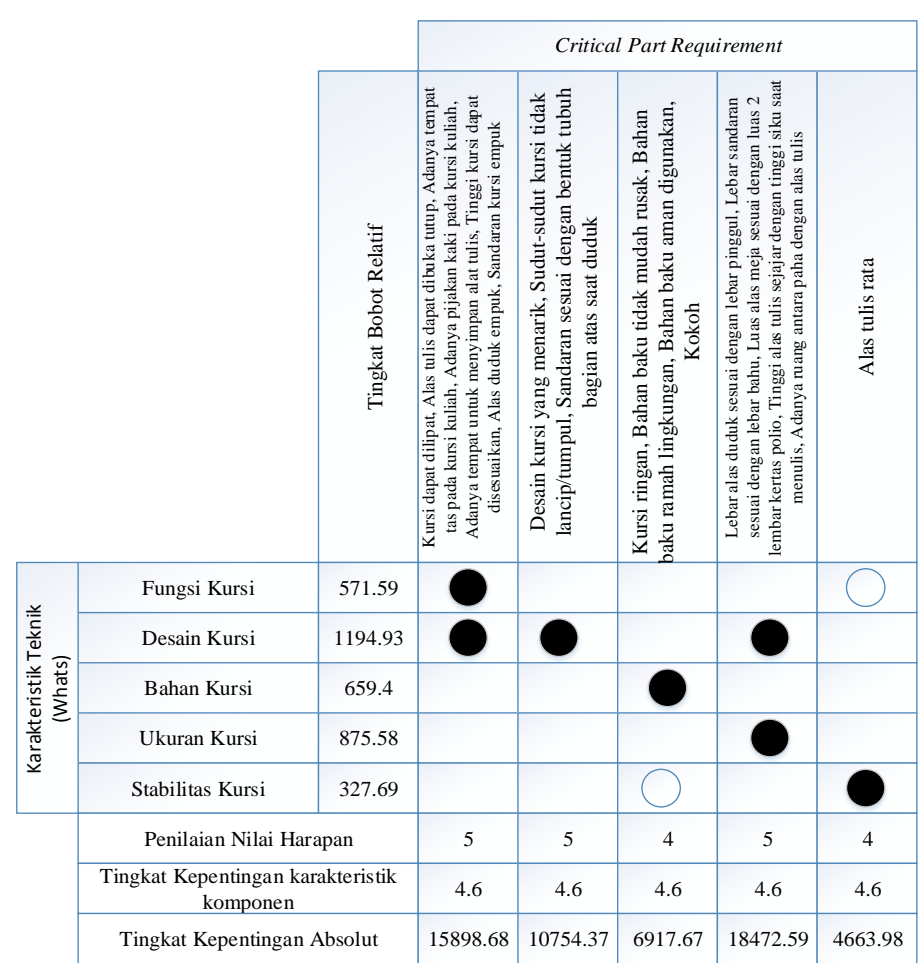

Gambar 2. Matriks Perancangan Komponen (Fasa 2)

Tabel 1. Daftar Karakteristik Komponen dan Karakteristik Proses Sesuai Dengan Urutan Prioritas

\begin{tabular}{|l|c|}
\hline \multicolumn{1}{|c|}{ Karakteristik Komponen } & $\begin{array}{c}\text { Karakteristik } \\
\text { Teknik }\end{array}$ \\
\hline $\begin{array}{l}\text { Lebar alas duduk sesuai dengan lebar pinggul, Lebar sandaran sesuai dengan lebar bahu, } \\
\text { Luas alas meja sesuai dengan luas 2 lembar kertas polio, Tinggi alas tulis sejajar dengan } \\
\text { tinggi siku saat menulis, Adanya ruang antara paha dengan alas tulis }\end{array}$ & Ukuran Kursi \\
\hline $\begin{array}{l}\text { Kursi dapat dilipat, Alas tulis dapat dibuka tutup, Adanya tempat tas pada kursi kuliah, } \\
\text { Adanya pijakan kaki pada kursi kuliah, Adanya tempat untuk menyimpan alat tulis, } \\
\text { Tinggi kursi dapat disesuaikan, Alas duduk empuk, Sandaran kursi empuk }\end{array}$ & Fungsi Kursi \\
\hline $\begin{array}{l}\text { Desain kursi yang menarik, Sudut-sudut kursi tidak lancip/tumpul, Sandaran sesuai } \\
\text { dengan bentuk tubuh bagian atas saat duduk }\end{array}$ & Desain Kursi \\
\hline $\begin{array}{l}\text { Kursi ringan, Bahan baku tidak mudah rusak, Bahan baku ramah lingkungan, Bahan } \\
\text { baku aman digunakan, Kokoh }\end{array}$ & Bahan Kursi \\
\hline Alas tulis rata & Stabilitas Kursi \\
\hline
\end{tabular}

Setelah karakteristik komponen dikelompokan kedalam karakteristik teknik maka selanjutnya yaitu mendeskripsikan karakteristik teknik kedalam paramater teknik yang sesuai dengan rancangan kursi kuliah yang akan dibuat. Perhatian utama (prioritas) dapat dilihat dari besarnya tingkat kepentingan absolut. Hasil Prioritas ialah ukuran kursi yang memiliki nilai terbesar sebasar 18472.59, fungsi kursi sebesar 15898.68, desain kursi sebesar 10754.37, bahan kursi sebesar 6917.67 dan stabilitas kursi sebesar 4663.98. Tahap akhir berupa perencanaan disain kursi kuliah yang ergonomis dengan memperhatikan dimensi tubuh (antropometri). Pengukuran dimensi tubuh (antropometri) merupakan faktor penting yang harus dilakukan dalam mendesain kursi kuliah yang ergonomis. 


\section{Perancangan Fasilitas Kursi Kuliah}

Perancangan fasilitas kursi kuliah dilakukan dengan dasar hasil kebutuhan dan keinginan mahasiswa/i yang belum terpenuhi. Perancangan kursi kuliah menggunakan metode Ergonomic Function Deployment (EFD). EFD memperhatikan kebutuhan mahasiswa yang memiliki kebiasaan menulis dengan tangan kiri. Tahapan meliputi menentukan rancangan fasilitas kerja yang baru, menentukan dimensi tubuh, pengukuran dimensi tubuh, dan pengujian data dan menentukan ukuran fasilitas kerja.

Hasil penelitian dibuat dua rancangan kursi kuliah :

1. Rancangan pertama adalah rancanga kursi dilengkapi dengan meja tulis yang menyatu dengan kursi tersebut

2. Rancangan kedua adalah rancangan satu set kursi dan meja tulis yang terpisah Pengukuran dimensi tubuh dilakukan dengan pengukuran secara langsung terhadap mahasiswa/i menggunakan alat ukur antropometer. Pengukuran dilakukan terhadap 98 responden. Dimensi tubuh yang diukur adalah Tinggi Popliteal (TP), Pantat Popliteal (PP), Lebar Pinggul (LP), Mata Kaki ke Lantai (MKL), Tinggi Siku Duduk (TSD), dan Tinggi Sandaran (TS). Hasil pengukuran digunakan untuk menentukan ukuran dimensi fasilitas yang dirancang (Tabel 2 \& 3). Ukuran setiap dimensi ditunjukan pada Gambar 3 dan 4.

Tabel 2. Ukuran Rancangan Pertama

\begin{tabular}{|c|l|l|c|c|c|c|}
\hline No & $\begin{array}{l}\text { Dimensi Fasilitas } \\
\text { kursi }\end{array}$ & $\begin{array}{c}\text { Dimensi Tubuh yang } \\
\text { digunakan }\end{array}$ & $\begin{array}{c}\text { Persentil } \\
\text { yang } \\
\text { Dipilih }\end{array}$ & $\begin{array}{c}\text { Ukuran } \\
(\mathbf{c m})\end{array}$ & Toleransi & $\begin{array}{c}\text { Ukuran } \\
(\mathbf{c m})\end{array}$ \\
\hline 1 & $\begin{array}{l}\text { Tinggi Sandaran } \\
\text { Duduk }\end{array}$ & Tinggi Sandaran (TS) & 50 & 42.65 & 2.35 & 45 \\
\hline 2 & $\begin{array}{l}\text { Tinggi Alas } \\
\text { Duduk dari Lantai }\end{array}$ & $\begin{array}{l}\text { Tinggi Popliteal } \\
\text { (PPL) }\end{array}$ & 50 & 51.79 & 3.21 & 55 \\
\hline 3 & $\begin{array}{l}\text { Panjang Alas } \\
\text { Duduk }\end{array}$ & Pantat Popliteal (PP) & 95 & 43.69 & 1.31 & 45 \\
\hline 4 & Lebar Alas Duduk & Lebar Pinggul (LP) & 95 & 37.03 & 2.97 & 40 \\
\hline 5 & $\begin{array}{l}\text { Tinggi Pijakan } \\
\text { kaki dari lantat }\end{array}$ & Mata Kaki ke Lantai & 95 & 11.79 & 3.21 & 15 \\
\hline 6 & lebar alas tulis & Panjang kertas polio & - & 35 & 0 & 35 \\
\hline 7 & $\begin{array}{l}\text { Panjang Alas } \\
\text { Meja }\end{array}$ & Lebar polio & - & 45 & 0 & 45 \\
\hline 8 & Tinggi laci & Ukuran alat tulis & - & 7 & - & 7 \\
\hline 9 & $\begin{array}{l}\text { Jarak antara } \\
\text { sandaran ke meja } \\
\text { tulis }\end{array}$ & $1 / 2$ Pantat Popliteal & 95 & 21.85 & 3.15 & 25 \\
\hline
\end{tabular}

Tabel 3. Ukuran Rancangan Kedua

\begin{tabular}{|c|c|c|c|c|c|c|c|}
\hline No & $\begin{array}{c}\text { Rancangan } \\
\text { Fasilitas kerja }\end{array}$ & $\begin{array}{c}\text { Dimensi Fasilitas } \\
\text { kursi }\end{array}$ & $\begin{array}{l}\text { Dimensi yang } \\
\text { digunakan }\end{array}$ & $\begin{array}{c}\text { Persentil } \\
\text { yang } \\
\text { Dipilih }\end{array}$ & Ukuran & Toleransi & $\begin{array}{l}\text { Ukuran } \\
(\mathrm{cm})\end{array}$ \\
\hline 1 & \multirow{3}{*}{ Kursi } & Tinggi Sandaran & $\begin{array}{l}\text { Tinggi Sandaran } \\
\text { (TS) }\end{array}$ & 50 & 42.65 & 2.35 & 45 \\
\hline 2 & & $\begin{array}{l}\text { Panjang tempat } \\
\text { duduk }\end{array}$ & $\begin{array}{l}\text { Pantat Popliteal } \\
\text { (PPL) }\end{array}$ & 95 & 43.69 & 1.31 & 45 \\
\hline 3 & & $\begin{array}{l}\text { Lebar tempat } \\
\text { duduk }\end{array}$ & $\begin{array}{l}\text { Lebar Panggul } \\
\text { (LEP) }\end{array}$ & 95 & 37.03 & 2.97 & 40 \\
\hline
\end{tabular}




\begin{tabular}{|c|c|c|c|c|c|c|c|}
\hline 4 & & $\begin{array}{l}\text { Tinggi tempat } \\
\text { duduk dari lantai }\end{array}$ & Tinggi Popliteal & 50 & 51.79 & 3.21 & 55 \\
\hline 1 & \multirow{4}{*}{ Meja } & Tinggi Meja & $\begin{array}{l}\text { Tinggi popliteal } \\
+ \text { Tinggi Siku } \\
\text { Duduk }\end{array}$ & 50 & 76.82 & 3.18 & 80 \\
\hline 2 & & lebar alas tulis & $\begin{array}{l}\text { Panjang kertas } \\
\text { polio }\end{array}$ & - & 35 & 5 & 40 \\
\hline 3 & & $\begin{array}{l}\text { Panjang Alas } \\
\text { Meja }\end{array}$ & Lebar polio & - & 45 & 5 & 40 \\
\hline 4 & & $\begin{array}{l}\text { Tinggi Pijakan } \\
\text { meja dari lantai }\end{array}$ & $\begin{array}{l}\text { Mata kaki ke } \\
\text { lantai }\end{array}$ & 95 & 11.79 & 3.21 & 15 \\
\hline
\end{tabular}
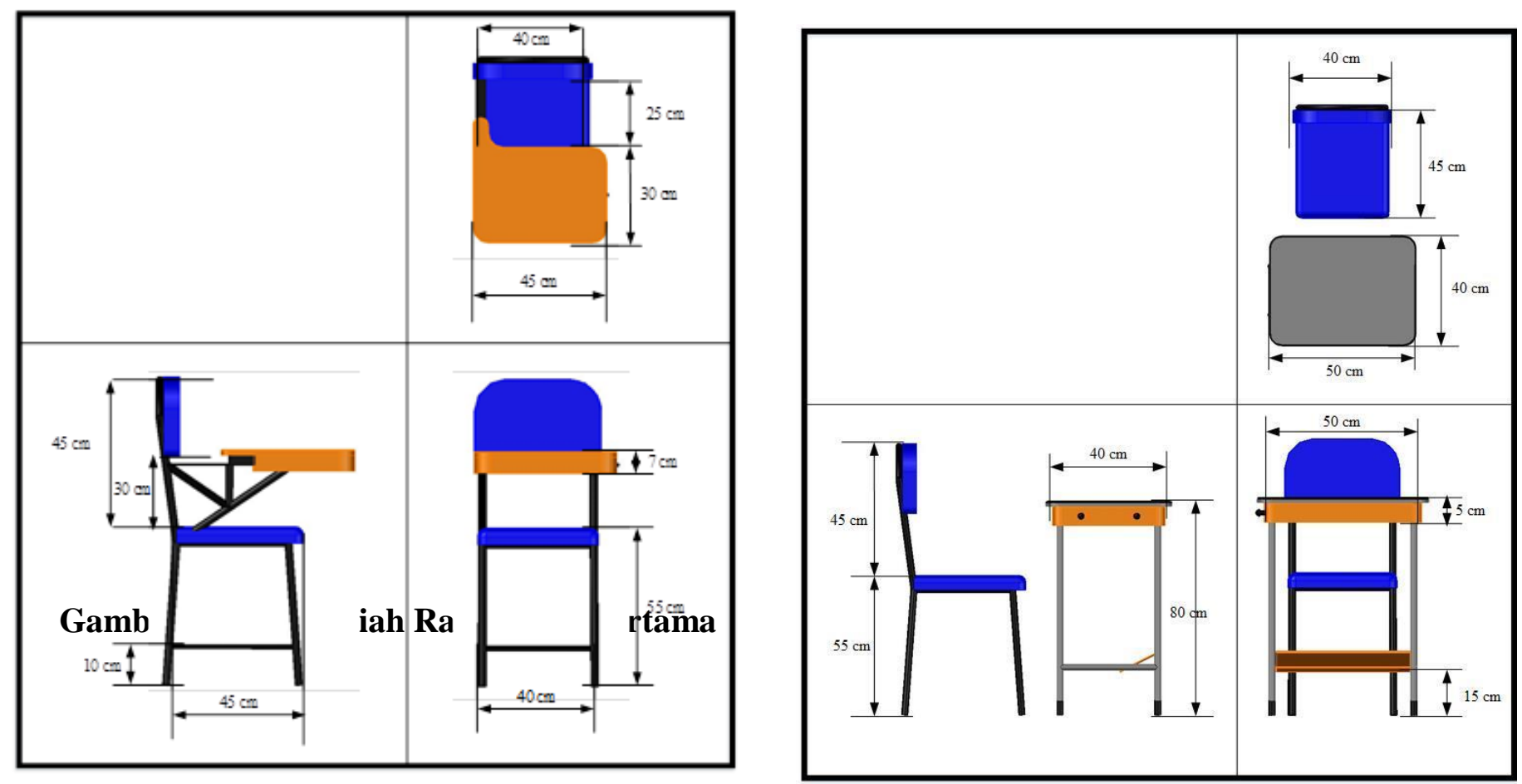

\section{Kesimpulan Dan Saran}

Kesimpulan dari penelitian yang telah dilakukan adalah sebagai berikut:

1. Ketiga kursi kuliah yang digunakan di UNISBA masih dirasakan kurang nyaman. Keluhan bokong/paha yang pegal karena bagian alas kursi keras dan lutut bagian kanan yang terkena bagian bawah alas meja. Kondisi seperti ini dapat menimbulkan resiko dikemudian harinya.

2. Berdasarkan penerapan menggunakan metode Ergonomic Fuction Deployment (EFD),yang menjadi perhatian utama (prioritas) ukuran kursi dan merancang kursi kuliah yang memperhatikan ukuran pengguna maka dilakukan dengan metode antropometri.

3. Perancangan fasilitas kursi kuliah yang ergonomis dilakukan dengan memperhatikan ukuran rata-rata dimensi tubuh mahasiswa/i. Perancangan yang yang dihasilkan dengan dua alternatif dengan menambahkan laci penyimpanan, menambahkan lebar alas tulis sesuai dengan lebar kertas polio. Sehingga dari yang diterapkan pada penelitian ini dapat menghasilkan kursi kuliah yang ergonomis dan sesuai dengan kebutuhan keinginanan mahasiswa/i. 
Adapun saran dari hasil penelitian adalah sebagai berikut :

1. Universitas harus menyediakan fasilitas yang ergonomis dalam proses pembelajaran, agar proses pembelajaran berjalan efektif.

2. Berdasarkan hasil kuesioner penelitian awal yang dilakukan pada penelitian ini selain kursi, yang harus diperbaiki adalah lingkungan. Oleh karena itu, saran untuk penelitian selanjutnya adalah perancangan lingkungan kelas.

\section{Daftar Pustaka}

Ekoanindiyo, F. A, 2010, Analisa Perancangan Kursi Kuliah Yang Ergonomi, Jurnal DINAMIKA TEKNIK Vol. IV, No. 1 Januari 2010 Hal64-76

Hutabarat, R. B, 2015, Rancang Bangun Ulang Kursi Kuliah Yang Ergonomis Berdasarkan Data Antropometri Mahasiswa Fakultas Teknik Universitas Tanjungpura, Jurnal TIN Universitas Tanjungpura Vol 1, No 1

Mulyono, G. 2010, Kajian Ergonomi Pada Fasilitas Duduk Universitas Kristen Petra Surabaya, Jurnal DIMENSI INTERIOR, VOL. 8, NO. 1, JUNI 2010: 44-51

Nurmianto, Eko. 2004. Ergonomi Konsep Dasar dan Aplikasinya. Guna Widya. Surabaya.

Sutalaksana, Anggawisastra dan Tjakraatmadja, 2006, Teknik Perancangan Sistem Kerja, ITB, Bandung. 